University of New Hampshire

University of New Hampshire Scholars' Repository

Faculty Publications

$11-1-2002$

\title{
Analysis of Vesicular Basalts and Lava Emplacement Processes for Application as a Paleobarometer/Paleoaltimeter
}

Dork L. Sahagian

Lehigh University

Alexander A. Prusevich

University of New Hampshire, Durham, alex.proussevitch@unh.edu

William D. Carlson

University of Texas at Austin

Follow this and additional works at: https://scholars.unh.edu/faculty_pubs

Comments

This is an article published by University of Chicago Press in The Journal of Geology in 2002, available online:

https://dx.doi.org/10.1086/342627

\section{Recommended Citation}

Sahagian, D., Proussevitch, A., \& Carlson, W. (2002). Analysis of Vesicular Basalts and Lava Emplacement Processes for Application as a Paleobarometer/Paleoaltimeter. The Journal of Geology, 110(6), 671-685. doi:10.1086/342627

This Article is brought to you for free and open access by University of New Hampshire Scholars' Repository. It has been accepted for inclusion in Faculty Publications by an authorized administrator of University of New Hampshire Scholars' Repository. For more information, please contact Scholarly.Communication@unh.edu. 


\title{
Analysis of Vesicular Basalts and Lava Emplacement Processes for Application as a Paleobarometer/Paleoaltimeter
}

\author{
Dork L. Sahagian, Alexander A. Proussevitch, ${ }^{1}$ and William D. Carlson ${ }^{2}$ \\ Climate Change Research Center (CRCC); Institute for the Study of Earth, Oceans, and Space (EOS); and \\ Department of Earth Sciences, University of New Hampshire, Durham, New Hampshire 03824, U.S.A. \\ (e-mail: dork.sahagian@unh.edu)
}

\begin{abstract}
A B S T R A C T
We have developed a method for determining paleoelevations of highland areas on the basis of the vesicularity of lava flows. Vesicular lavas preserve a record of paleopressure at the time and place of emplacement because the difference in internal pressure in bubbles at the base and top of a lava flow depends on atmospheric pressure and lava flow thickness. At the top of the flow, the pressure is simply atmospheric pressure, while at the base, there is an additional contribution of hydrostatic lava overburden. Thus the modal size of the vesicle (bubble) population is larger at the top than at the bottom. This leads directly to paleoatmospheric pressure because the thickness of the flow can easily be measured in the field, and the vesicle sizes can now be accurately measured in the lab. Because our recently developed technique measures paleoatmospheric pressure, it is not subject to uncertainties stemming from the use of climate-sensitive proxies, although like all measurements, it has its own sources of potential error. Because measurement of flow thickness presupposes no inflation or deflation of the flow after the size distribution at the top and bottom is "frozen in," it is essential to identify preserved flows in the field that show clear signs of simple emplacement and solidification. This can be determined by the bulk vesicularity and size distribution as a function of stratigraphic position within the flow. By examining the stratigraphic variability of vesicularity, we can thus reconstruct emplacement processes. It is critical to be able to accurately measure the size distribution in collected samples from the tops and bottoms of flows because our method is based on the modal size of the vesicle population. Previous studies have used laborious and inefficient methods that did not allow for practical analysis of a large number of samples. Our recently developed analytical techniques involving high-resolution x-ray computed tomography (HRXCT) allow us to analyze the large number of samples required for reliable interpretations. Based on our ability to measure vesicle size to within $1.7 \%$ (by volume), a factor analysis of the sensitivity of the technique to atmospheric pressure provides an elevation to within about $\pm 400 \mathrm{~m}$. If we assume sea level pressure and lapse rate have not changed significantly in Cenozoic time, then the difference between the paleoelevation "preserved" in the lavas and their present elevation reflects the amount of uplift or subsidence. Lava can be well dated, and therefore a suite of samples of various ages will constrain the timing of epeirogenic activity independent of climate, erosion rates, or any other environmental factors. We have tested our technique on basalts emplaced at known elevations at the base, flanks, and summit of Mauna Loa. The results of the analysis accurately reconstruct actual elevations, demonstrating the applicability of the technique. The tool we have developed can subsequently be applied to problematic areas such as the Colorado and Tibetan Plateaus to determine the history of uplift.
\end{abstract}

\section{Introduction}

Epeirogenic uplift and subsidence has been documented for depositional lowlands whose sedimentary and erosional histories reflect changes in depositional environments caused by sea level variations or local

Manuscript received June 7, 2001; accepted February 5, 2002.

${ }^{1}$ CCRC, EOS, University of New Hampshire, Durham, New Hampshire 03824, U.S.A.

${ }^{2}$ Department of Geological Sciences, University of Texas, Austin, Texas 78712, U.S.A. tectonics (Sahagian 1987, 1988; McDonough and Cross 1991; Loomis and Ingle 1994; Luo and Vasseur 1995; Nadin and Kusznir 1995; Tudhope et al. 2000). These methods cannot generally be used for highland areas because they rely on sedimentation and preservation, base-level erosion such as wave-cut terraces, marine faunal communities, and other proxies that are inapplicable to highlands. Methods applicable to highlands are typically based on proxies

[The Journal of Geology, 2002, volume 110, p. 671-685] @ 2002 by The University of Chicago. All rights reserved. 0022-1376/2002/11006-0003\$15.00 
that are sensitive to climatic variations. Consequently, a method to measure paleoelevation that is reasonably independent of climatic variations can not only more reliably determine the timing and magnitude of tectonic and epeirogenic events but can also be inverted in concert with climate-sensitive proxies to reconstruct paleoclimatic variations.

Paleoelevations would be useful to document because a definitive understanding of uplift histories would shed light on a few key geologic issues such as paleogeography, paleoclimatology, lithospheric thermal structures, and mantle processes. While paleogeographic reconstructions have been relatively straightforward and accurate for marine and low-elevation areas (Ziegler et al. 1979, 1985; Sahagian 1987, 1988, 1989; McDonough and Cross 1991), geological approaches that require the deposition and preservation of sediments are problematical for high elevations. Traditional paleofloral approaches can determine temperatures (Wolfe and Shorn 1989; Gregory and Chase 1992, 1994; Wolfe 1995; Gregory and McIntosh 1996; Wolfe et al. 2000) but cannot separate the effect of elevation change from climate change. This is particularly important in light of the potential effect of elevation changes on climate (Barron 1985; Kutzbach et al. 1989, 1993; Ruddiman and Kutzbach 1989; Molnar and England 1990). Some explanations of uplift mechanisms call for changes in the thermal regime of the lithosphere and underlying mantle (Bird 1979; Morgan and Swanberg 1985; Beghoul and Barazangi 1989; Lucchitta 1990; Beghoul et al. 1993). However, without knowing the timing and extent of uplift, these explanations cannot be verified or quantified. Mantle processes that are responsible for epeirogeny at various scales (Dickinson and Snyder 1979; Parsons et al. 1994; Parsons and McCarthy 1995) can be better constrained if the timing and amount of surface uplift is known.

Previous paleoelevation proxies commonly depended on factors other than paleoelevation. For instance, geomorphologic approaches involving river downcutting also depend on changes in base level. Sedimentation rates also depend on erosion rates, which are greatly increased in glacial times. Paleoflora reflect temperature that depends on climate changes, and enthalpic calculations also depend on longitudinal variations in enthalpy (but the errors have been estimated to be relatively small [Wolfe et al. 1998]). Further, no method based on flora can be used at high elevations (above the tree line) or where the necessary flora are absent.

When a proxy such as paleoflora or geomorphology records more than one variable, it leads to ambiguous interpretations and considerable debate
(Morgan and Swanberg 1985; Meyer 1992; Gregory and Chase 1994; Parsons and McCarthy 1995; Spencer and Patchett 1997; Lucchitta and Morgan 1998). This problem with proxies highlights the need to determine paleoelevation independent of other factors. Forest et al. (1995) stated that "ideally, paleoelevations would be inferred directly from estimates of paleopressure" (p. 347).

We have developed a technique for determining paleoelevation on the basis of basalt vesicularity (Gregory 1994; Sahagian and Maus 1994). Our technique is based on the difference in internal pressure between bubbles at the top and base of lava flows. At the top, the pressure is simply atmospheric pressure, while at the base, there is an additional $\rho g H$ "lavastatic" pressure. Vesicularity can measure changes in sea level pressure over Earth history and would involve analysis of ancient basalts (such as the Keweenawan Basalts) emplaced at or near sea level. Conversely, because most researchers agree that sea level pressure has not changed significantly in the Cenozoic (Abe and Matsui 1986; Azbel and Tolstikhin 1990, 1993; Williams and Pan 1992; Tajika and Matsui 1993), basalt vesicularity can be used to determine paleoelevation for Cenozoic events.

Given our understanding of processes of lava flow vesiculation and emplacement (Sahagian 1985; Sahagian et al. 1989), the accuracy of the vesicular lava method depends on our ability to determine two properties of lava flows: size distributions of vesicles and flow emplacement history. We have recently developed practical methods for determining the size distribution of vesicles in lava samples based on high-resolution x-ray computed tomography (HRXCT; Proussevitch and Sahagian 1998, 2001; Song et al. 2001). Our preliminary investigation involved plastic casts (Sahagian and Maus 1994) and had error bars of over a kilometer of elevation. Our new techniques have reduced this uncertainty to about $\pm 400 \mathrm{~m}$, enabling quantitative analysis of the amount as well as timing of epeirogeny. In addition, it allows the rapid analysis of a large number of samples, reducing uncertainties due to local variations in basalt vesicularity by multiply redundant sampling.

The second aspect of lava flows that must be determined is flow emplacement history. Because the calculation of ambient pressure and thus paleoelevation is based on flow thickness at the time the bubbles at the top and base of the flow solidified, it is critical to be sure that flow thickness did not vary before the entire flow solidified. Inflation and deflation of lava flows is a common process during emplacement, so we have developed criteria for the identification of inflated, deflated, and sim- 


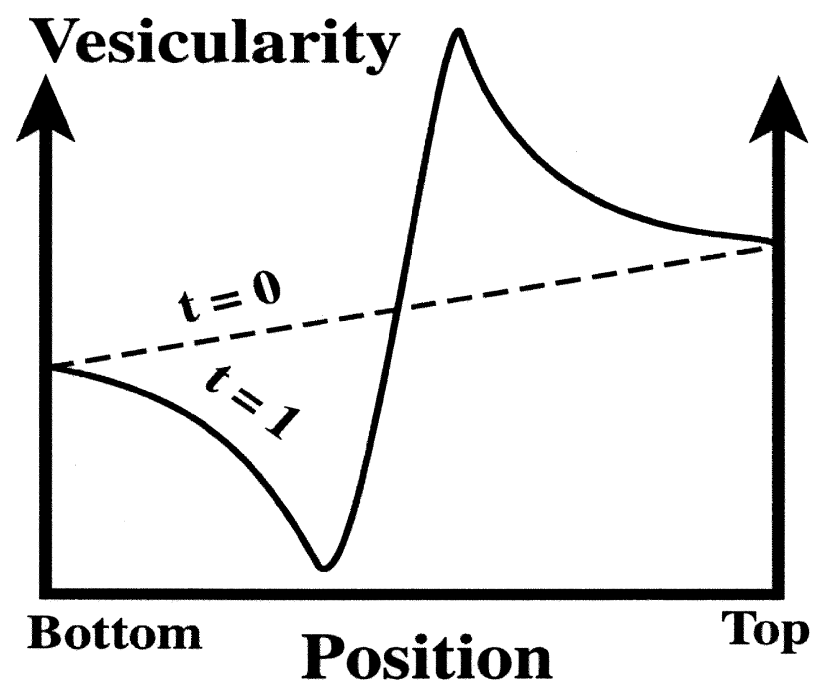

Figure 1. Typical vesicularity profile before and after vesicle rise during lava solidification in a 3-m flow.

ply emplaced flows. Only flows with simple emplacement can be used in paleoelevation analysis.

\section{Vesicle Zonation}

Vesicular zones develop in lava flows because of buoyant bubble rise and concurrent crystallization of the lava from top and bottom (Sahagian 1985). As the bubbles rise from the base, they are quickly caught by a rapidly rising crystallization front. Like the cooling of the ocean lithosphere, crystallization fronts progress at a speed proportional to the square root of time. They start quickly, then slow down as they are more insulated by the surrounding lava. Thus virtually all bubbles are "frozen in" at the base of the flow, while only the smallest bubbles are caught by the crystallization front higher up (the larger ones can escape by their more rapid rise through the lava). The situation at the top of the flow is the same, except that bubbles rise headlong into the dropping crystallization front. Thus the very top includes all bubbles as they were originally emplaced (just as at the very bottom).

The vesicularity of the flow interior is the result of bubble rise and coalescence, with a specific and readily identifiable size distribution as a function of stratigraphic position in the flow (fig. 1; Sahagian et al. 1989). In the center of the flow, bubbles have the longest time to rise from the lower parts and coalesce with each other. For thicker flows, the two crystallization fronts eventually become so slow that all bubbles can outrun the lower front and rise to be caught by the upper front. This results in a central massive zone containing no vesicles, a phenomenon commonly observed in the field in flows thicker than $3 \mathrm{~m}$ (fig. 2).

Above the central massive zone is the upper vesicular zone. Because the upper crystallization front "catches" bubbles rising from the flow interior, the upper vesicular zone includes a large number of bubbles derived from a wide range of depths that have coalesced en route to form large bubbles. This makes a highly vesicular zone immediately above the massive zone, where the upper crystallization front moves slowly enough to intercept a large number of bubbles as they rise from a wide range of depths. The vesicularity profile of the upper vesicular zone is readily observed in the field and is an important hydrologic feature in lava flows due to its high permeability.

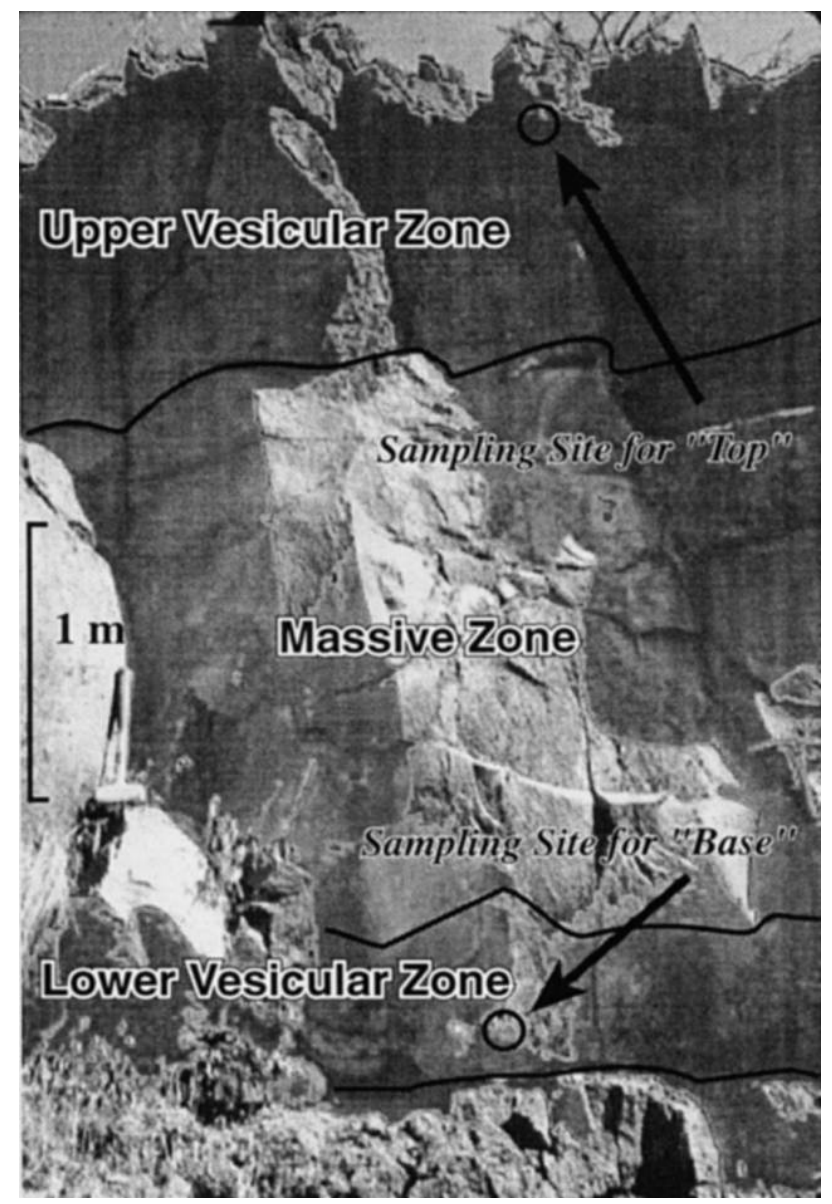

Figure 2. Typical outcrop of vesicular basalt. Note upper and lower vesicular zones and massive vesicle free region in the interior of this 5-m flow. 


\section{Paleopressure from Vesicular Basalts}

Vesicle size distributions in lava flows can be used as a measure of paleopressure at the site of emplacement. When a lava is emplaced, bubbles containing equal amounts of gas at the base and top of a flow are subject to different total pressures due to difference in overburden. The atmospheric pressure dependence of vesicle size can be expressed by the ratio of vesicle size distributions at the top and bottom of a flow:

$$
\frac{V_{\mathrm{t}}}{V_{\mathrm{b}}}=\frac{P+\rho g H}{P},
$$

where $V_{\mathrm{t}}$ and $V_{\mathrm{b}}$ are the volumes of the modal bubble sizes at the quenched top and bottom of the flow, respectively (measurable), $\rho$ is lava density (known), $g$ is gravity (known), $H$ is flow thickness (measured), and $P$ is atmospheric pressure at emplacement. Paleopressure can thus be determined because all other variables are known. We use modal instead of average size because it is less sensitive to the presence or absence (or loss) of a few large vesicles. (In fact, we use the entire size distribution to determine the modal ratio for highest accuracy.) Likewise, simple bulk rock density measurement would be subject to large errors (particularly if vesicles are filled). The formulation is independent of lava viscosity because bubbles reach physical equilibrium with the surrounding lava long before crystallization freezes them into place. Any shear during transport would not affect the ratio of modal bubble sizes (top/bottom) because significant lateral variations in top or bottom vesicularity (modal sizes) would not be expected, nor have they been observed in previous studies (Sahagian et al. 1989; Sahagian and Maus 1994). Any bubble nucleation during crystallization would produce the smallest vesicles in the observed population and would thus not affect the modal vesicle size (typically $1 \mathrm{~mm}$ modal diameter for basalts and slightly smaller for more silicic flows).

\section{Lava Emplacement History}

For the purpose of paleoelevation measurement, it is critical to sample only lavas exhibiting clear evidence of simple emplacement histories. Vesicularity profiles can clearly be observed in the field and compared to "ideal" vesicularity (Sahagian 1985; Sahagian et al. 1989). The reason this is important is that we must be sure that the upper and lower $10 \mathrm{~cm}$ (or so) of the flow solidified after the flow reached its final thickness (thickness to be measured in the field). If the lava is emplaced without late-stage inflation or any other complicating factors (after top and base have crystallized to a significant distance into the flow), the vesicularity profile will include vesicular zones in the upper and lower parts of the flow (figs. 1,2).

Complications would be introduced by inflation or deflation after the top and bottom of the flow have solidified. During flow cooling and solidification, bubbles rise from the base, being "chased" by the lower crystallization front, and move upward toward the upper crystallization front. This movement (and associated bubble coalescence) alters the distribution of the bubbles within the flow in a predictable manner (Sahagian 1985). If additional lava were to surge into the site after significant movement of bubbles and crystallization fronts, but before the two crystallization fronts meet for final solidification of the flow, the standard vesicularity profile would be altered. The newly introduced lava would bring with it its own (unevolved) bubble distribution that would then reside in the center of the older, evolved material. The bubbles within the new lava would then begin to rise, making a new vesicularity pattern within the older pattern. Again, before crystallization fronts merge, additional inflation could occur with new lava introducing new bubbles. This process can occur any number of times, resulting in a series of nested units with their own vesicular zones. Inflation after partial solidification is thus readily identified by multiple layers of small vesicles in a relatively thick flow (e.g., $>3 \mathrm{~m}$ ).

Alternatively, after initial emplacement and crystallization at the top and bottom of a flow, deflation could occur, and lava could drain away from the flow interior, resulting in a thinning of the flow after the vesicles at the top and bottom "recorded" the ambient atmospheric pressure. This would cause the upper vesicular and lower vesicular zones to be brought in closer contact with each other at an early stage of solidification, without the time for the crystallization fronts to intercept the evolving bubble distribution within the flow interior. This would prevent the development of a highly vesicular upper vesicular zone if deflation occurred early and would remove a massive zone if deflation occurred late. Deflation can thus be identified by a continuous and relatively uniform vesicularity profile, lacking in a vesicle-free zone in the middle of the flow, and/or by large, coalesced vesicles in a thin flow with no corresponding vesicle-free zone.

These characteristics of lava flows provide insight into the emplacement history of the flow and must be considered when assessing field sites for paleoelevation studies. An understanding of vesi- 


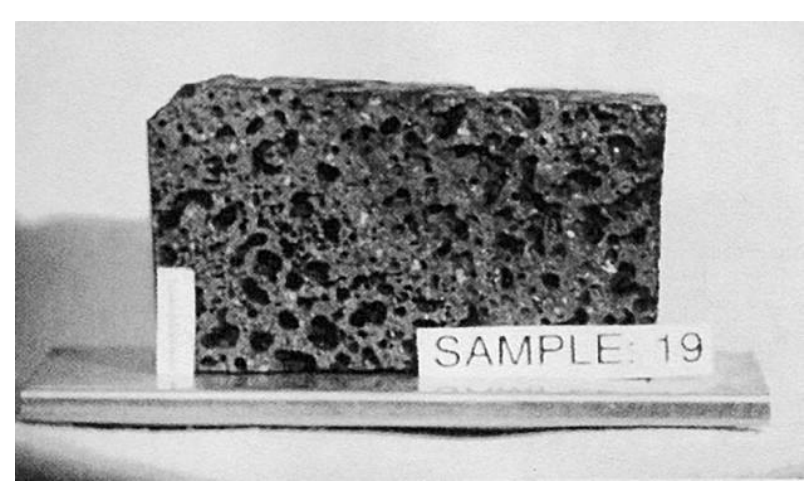

Figure 3. Vesicular basalt sample

cularity and its dependence on emplacement history can also be used to reconstruct eruption sequences during an eruption phase.

\section{Basalt Vesicularity Measurement Techniques}

Calculation of paleopressure and thus the success of this approach to determining paleoelevation depends upon our ability to accurately measure the size distribution of vesicles in hand samples of basalt (fig. 3). Three basic methods have been used to measure vesicle size distributions.

Plastic Casts. In previous studies, a technique was developed in which plastic casts were made of the vesicles. Samples were analyzed in the laboratory to determine vesicle size distributions by impregnating the samples with a plastic polymer, dissolving the basalt in $\mathrm{HF}$, and measuring the plastic

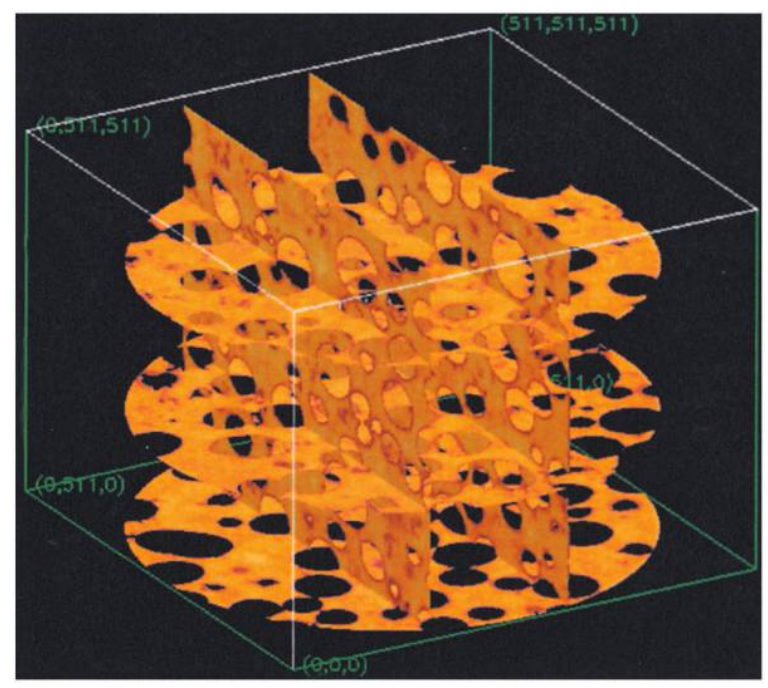

Figure 4. Image slices through sample casts of the vesicles. The plastic casts were resistant to the effects of HF, so they reliably represented the actual vesicle sizes and shapes but were difficult to measure accurately and very tedious to work with (Sahagian et al. 1989).

After enduring the procedure involving plastic casts, it was recognized that two-dimensional (2D) statistical methods or some form of threedimensional (3-D) imaging would be necessary for the technique of using vesicular basalts for paleoelevation studies to be practical. Rapid analysis would permit a greater number and larger samples to be counted, thereby reducing the potential effects of local vesicularity variations or biases caused by presence or absence of individual vesicles of the largest size. Also, with multiple samples, it would be possible to identify and discard other unforeseen vagaries in individual samples, greatly increasing the accuracy of the analysis.

Stereology (2-D Cross Sections). One can determine vesicle size distributions from 2-D cross sections of hand samples (Underwood 1970; Dullien 1973; Russ 1986; Marsh 1988; Mangan 1990; Toramaru 1990). Sample cross sections can be optically scanned and the data numerically processed to produce 2-D size distributions, which can be converted to 3-D with stereology. Stereology is a mathematical tool for quantitative analysis of 3-D geometry, topology, structure, and statistics on the basis of 2-D information. Until recently, stereological formulation had only been applicable to spherical particles. To treat nonspherical particles such as vesicles, we refined stereological methods and developed appropriate conversion coefficients for 2-D to 3-D con-

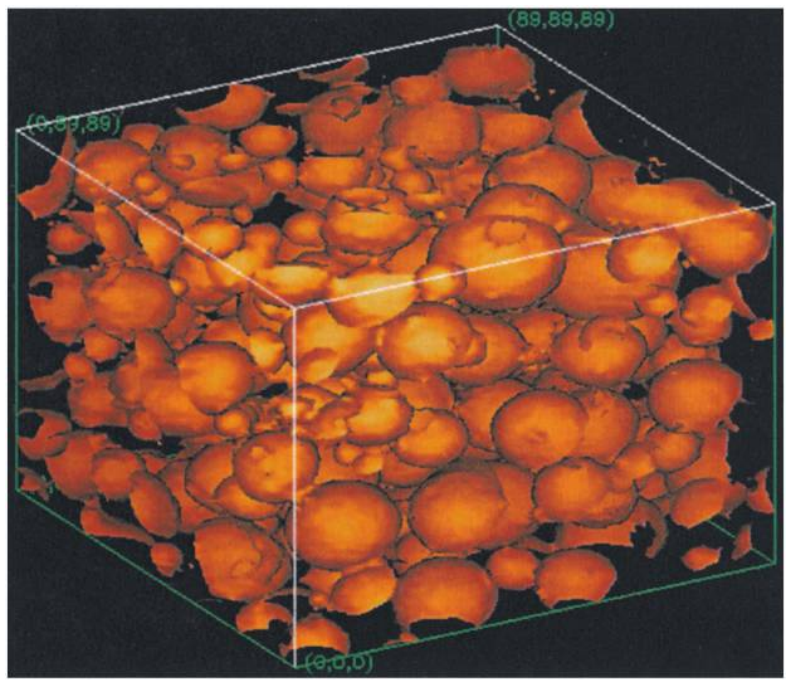


version (Sahagian and Proussevitch 1998) without a priori assumed size distribution (e.g., lognormal, unimodal, etc.; Higgins 1994; Peterson 1996).

High-Resolution X-Ray Computed Tomography (3-D Imaging): Imaging Procedure. X-ray computed tomography has long been used as a diagnostic medical tool, and the recent advent of instruments with substantially greater penetrating power and greatly increased spatial resolution (HRXCT) has allowed the technique to find widespread application in the geosciences (Rowe et al. 1997). High-resolution xray computed tomography measures the transmission of $x$-rays through an object; contrast in the images is produced by differences in the linear attenuation coefficient for $\mathrm{x}$-rays in different materials within the object's interior. High-resolution $\mathrm{x}$ ray computed tomography can be used to produce highly detailed 3-D reconstructions of internal features in a completely nondestructive way. The digital character of HRXCT data facilitates accurate measurement of the sizes, shapes, and locations of features; in our case, it allows measurement of vesicles with speed, precision, and accuracy greatly superior to the other methods just described.

The attenuation of $\mathrm{x}$-rays of a given energy is a function primarily of mass density (and secondarily of atomic number) in the material being irradiated, so HRXCT images closely approximate the density structure of objects. In the procedure applied in this study, the object being investigated (a cylindrical core of vesicular basalt) is rotated around a vertical axis in the path of a horizontal fan-beam of $\mathrm{x}$ radiation as measurements of attenuation are made. Tomographic reconstruction of the attenuation measurements produces a single 2-D image, or "slice." The object is then translated vertically, and the process is repeated. Contiguous slices can be stacked (fig. 4) to provide a 3-D image of internal structure (fig. 5). For a more detailed description of HRXCT imaging of geological materials, consult Ketcham and Carlson (2001). Figures 4 and 5, images of a sample from Mauna Loa, illustrate the extent of the previously available level of analysis that allowed for pictorial imaging but not quantitative analysis. To address the latter, the necessary numerical formulation to directly compute size distributions from the computed tomography (CT) scan data were developed by Proussevitch and Sahagian (2001).

\section{Analytical Procedures}

Image Analysis. We did our measurement of vesicle size distributions by using our numerical analysis techniques (Proussevitch and Sahagian 2001).
We used the offset of the size distributions (most easily visualized as offset of the modes) between the tops and bottoms of the sampled flows to determine paleoatmospheric pressure and thus paleoelevation, using the standard atmospheric lapse rate. We have compared the results of HRXCT analyses with those of plastic casts and stereology (Sahagian et al. 1989; Sahagian and Proussevitch 1998). The results indicate that 3-D HRXCT imaging is the most effective way to quantify the size and shape distribution of vesicles in basalts. In addition, connectivity (permeability) can be constrained. The latter is not possible with other methods.

Because grayscale levels in the images reflect sample density, voxel fragmentation can discriminate void voxels from matrix voxels. We developed and used a logical threshold method in which we find a grayscale level that fixes a threshold between void and matrix voxels for each $3-\mathrm{D}$ voxel data set (for each sample). The threshold level is picked from the spot where the second derivative of grayscale levels along the profile across a border of large vesicle is equal to zero. In other words, this is the point where the curvature of the grayscale-level profile at the vesicle border changes from positive to negative. After this fragmentation procedure, we reduced data to a 3-D Boolean array with 1 bit data per point (voxel) where 0 is void and 1 is matrix.

The Boolean voxel array (data set) is used to run object recognition software (Proussevitch and Sahagian 2001) in order to construct a data set of individual vesicles from stand-alone and complex structures resulting from interconnected or partially coalesced bubbles. The vesicle data set contains a variety of information for each vesicle such as its own ID, coordinates within the master data set, subset of voxels (exact shape of the vesicle), volume, surface, radius of equal-volume sphere, coordination number with neighboring vesicles, IDs of adjacent interconnected vesicles, interface surface with each of them, nine parameters of closest 3-D ellipsoid that approximates the vesicle, and standard deviation between the surfaces of the two.

In the analysis of images rendered using $\mathrm{CT}$, the most significant technical difficulties arise in defining the boundaries of individual objects. The analysis is complicated by deformed and partially coalesced vesicles that are difficult to interpret because of finite CT resolution. If resolution is insufficient to clearly image thin rock septa between vesicles, one may erroneously infer the existence of vesicles larger and more topologically complex than actually exist. In order to overcome these obstacles, it was necessary to define numerical criteria for separating apparently complex objects into their actual simpler 
components. We developed an algorithm to separate vesicles that had become partially coalesced either in the lava or in the scanning process on the basis of the narrow waist between them, thereby restoring to each its separate identity and volume (Sahagian and Proussevitch 1998; Proussevitch and Sahagian 2001). Removing layers of voxels exposed at the object's surface eventually resulted in separation of partially coalesced objects, and so each could be assigned an individual identity for statistical analysis (Proussevitch and Sahagian 2001).

Numerical Analysis. Analysis of HRXCT involved the following steps.

Read Input Image Data (Scan Slices). There are typically about 350 slice images with $512 \times 512$ pixels. Field of view is $22 \mathrm{~mm}$ with $47-\mu \mathrm{m}$ resolution. The elementary unit of this data set is the voxel (3-D pixel). Slice spacing is always the same as the resolution to make cubic voxels. Stacking images in a 3-D array makes an initial data set ready for 3-D image rendering and object processing. Each voxel contains information about the local density of the sample. Computed tomography images are recorded in 8-bit gray scale, and the range is calibrated to the appropriate density range.

Mask Actual Sample within Master Voxel Array. Masking the actual sample excludes the region outside the sample from the analysis. Masking is not a simple rectangular cutoff but, rather, a cylindrical or more complex shape to utilize the maximum available volume of the sample within the 3-D master array of voxels.

Identify Vesicles. Voids (vesicles) are the easiest entities to identify within a color-density scale because of the maximum possible density (color) contrast with rock. Carbonate- or silica-filled vesicles can also be readily identified. We can adjust density contrast sensitivity to be set according to the vesicle-filling material.

Identify and Catalog All Interconnected Vesicles as "Raw Objects" (Structures). As we indicated above, "interconnected" does not mean that objects (vesicles) are actually interconnected or partially coalesced. Individual vesicles can appear as interconnected if they are closely spaced and CT image resolution is lower than intervesicle film thickness. There are often hundreds or even thousands of individual vesicles (objects) in a single "raw" structure.

Split Apart Partially Coalesced/Touching/Closely Spaced Vesicles into Their Separate Identities for Cataloging. This step is particularly important because manual separation would make the analysis impractical. The procedure is based on "peeling" (Proussevitch and Sahagian 2001). In the nu- merical procedure, successive layers of voxels are peeled away, and the join between the objects shrinks and finally disappears. At this point, it is possible to reassemble the original configuration and assign individual identities to the objects as they reappear. The peeling procedure can separate any combination of voxelized objects that are joined by a waist narrower than either of the objects themselves. One can specify as appropriate how much narrower a waist must be to cause the peeling procedure to separate any two objects.

Generate Full Population Statistics from the Catalog of Individual Vesicles. The catalog contains 26 parameters for each vesicle (object) including volume, aspect ratio, tangential radius, surface area, interfaces with neighboring vesicles, list of neighboring vesicles, coordination number, 10 parameters for closest ellipsoid approximation, and various other characteristics. Each of these is calculated with a numerical routine that operates on the population of separated individual objects.

The output of the analysis of a typical basalt sample results in 5000-15,000 vesicles-quite sufficient for a robust statistical analysis (fig. 6) to be used in the paleopressure calculations. The resulting paleopressures will provide paleoelevation using the "standard atmosphere" relation of elevation and pressure (fig. 7). Paleoelevation can then be determined from the paleopressure using the known relation of pressure and elevation (standard atmosphere) because sea level pressure is known. Determining paleoelevations in this way is particularly significant in that there are few other paleoelevation indicators in highland areas where basalts are often emplaced.

\section{Sample Collection}

The application of this simple approach to natural lavas for the purpose of determining atmospheric pressure requires certain conditions to be satisfied.

1. Lava was extruded with a well-mixed population of bubbles so that their initial mass distribution is not a function of vertical position in the flow. This is typically the case in effusive eruptions that produce fluid lava (rather than ash).

2. The lava flow experienced a simple emplacement history, meaning that the flow was erupted from a volcanic vent, traveled to its final resting place, and solidified in situ without further disturbance. Examples of disturbance include reinflation by additional lava after top and base had solidified, deflation by drainage of interior lava, and additional lava emplacement over the partially solidified flow 


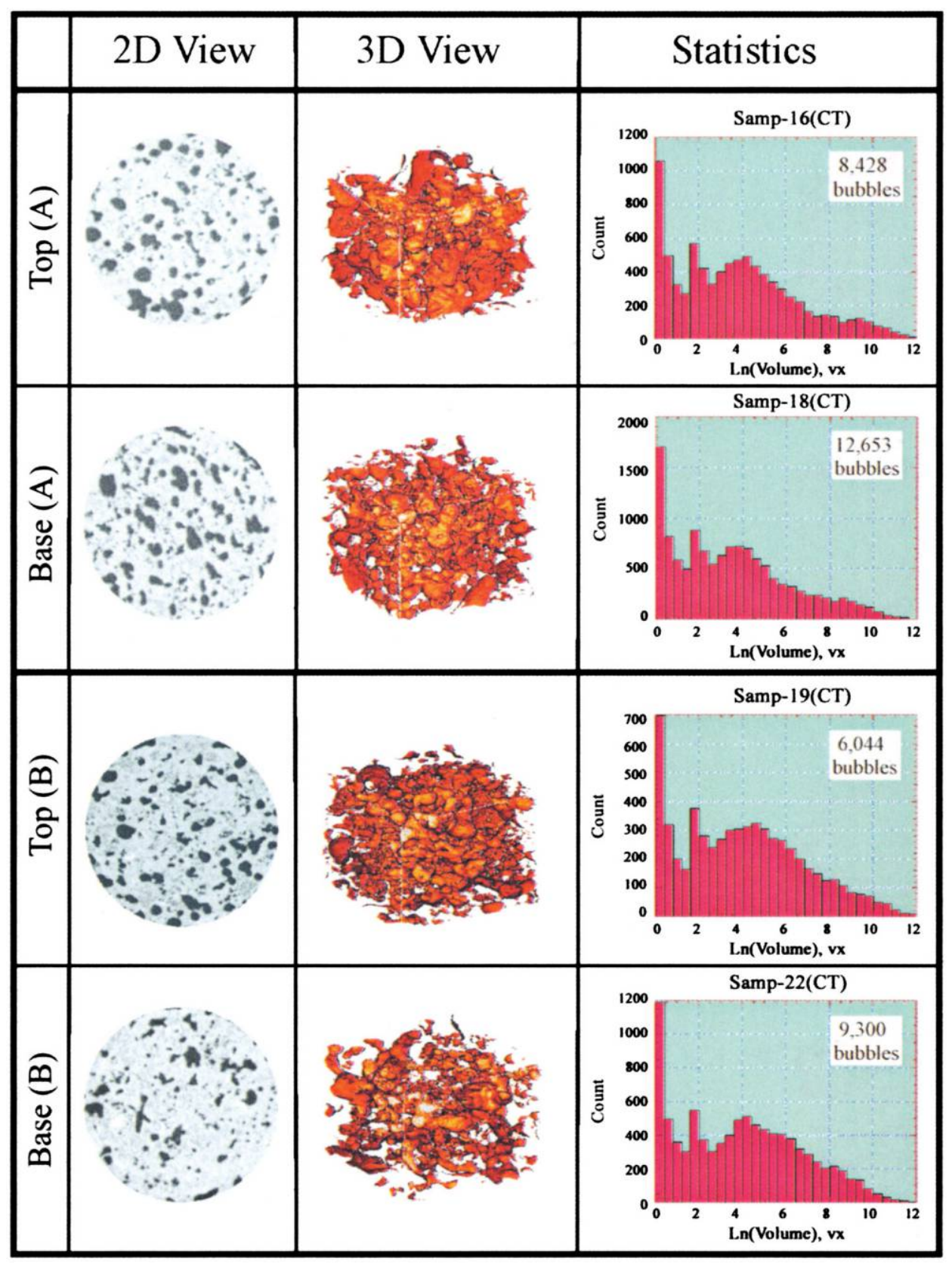

Figure 6. Results of analysis from two flows on Mauna Loa; $A$ refers to location 6, and $B$ to location 7

causing the solidified top to shear away from the emplacement site.

3. There were no sources outside of the flow such as soil moisture or burning vegetation to introduce bubbles into the flow before solidification of the top and bottom.

Fortunately, each of these conditions can be assessed in the field, and appropriate sites can be sampled on the basis of simple emplacement history.

We have used the techniques we have developed with vesicular basalts to "measure" the known elevation of the base and summit of Mauna Loa (as was done earlier using plastic casts; Sahagian and Maus 1994). Figure 8 shows sampling localities on Mauna Loa. The proper vesicularity profile (fig. 1) is so easy to recognize when one is standing in front of a cross section of a lava flow that the most difficult part of the fieldwork is simply finding localities in which the base of the flow is exposed. Potential sampling sites are ubiquitous at the summit 


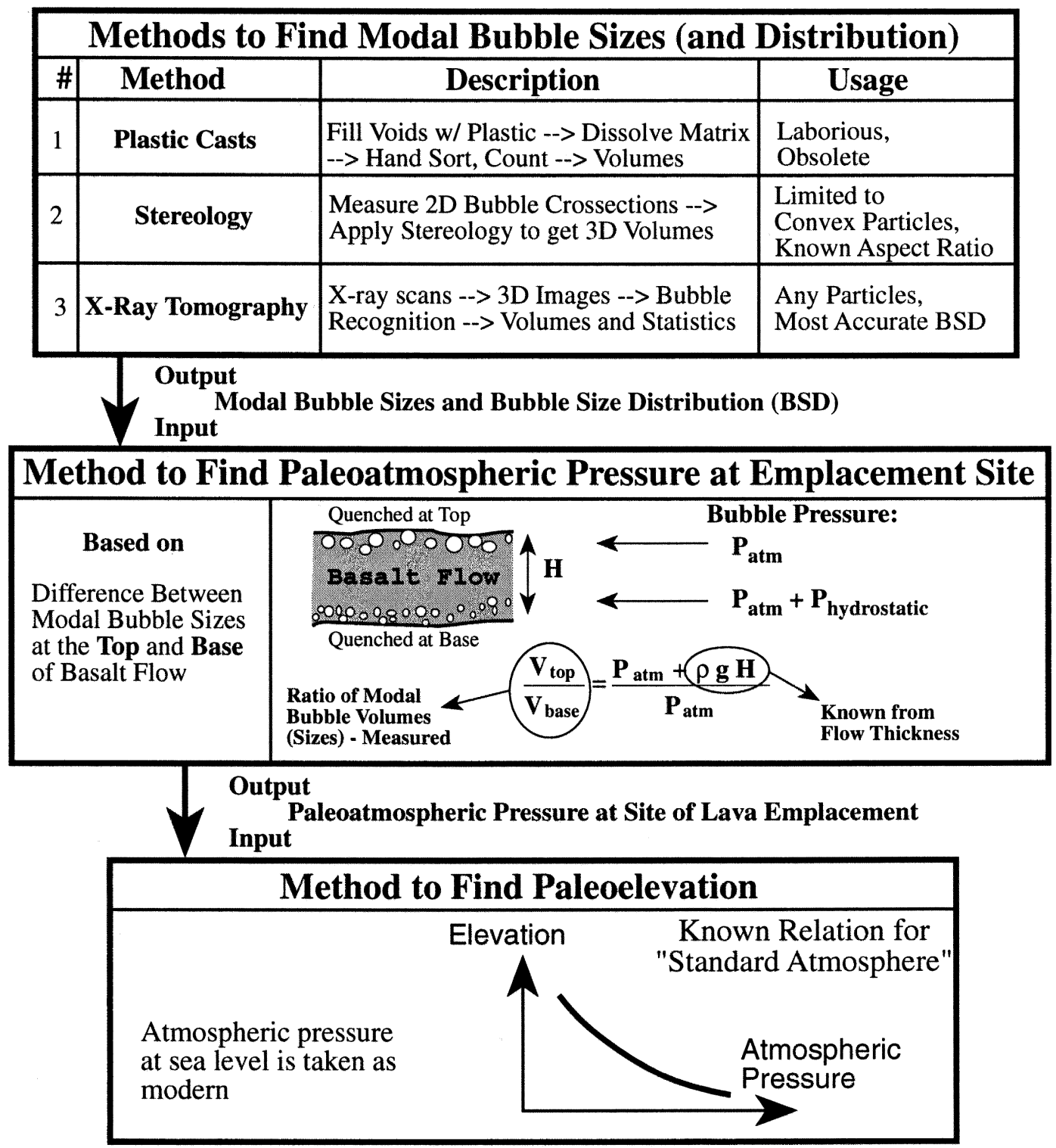

Figure 7. Flowchart of methodology for determining paleoelevation from vesicular basalts

of Manua Loa along many cracks and fissures near the crater rim. Many recent flows have been well mapped, and there are small lobes available for sampling. These exhibit vesicularity profiles that reflect simple emplacement history, the lava having been apparently removed from the main channels of the lava flows.

Sampling sites are also available at low elevation in Hilo and elsewhere. Roadcuts, stream channels, and natural cliffs and fissures provide many sampling sites near the terminus of the flows or in breakout lobes. With the large number of potential sampling sites available at the base and summit, the only constraint on the number of samples was funds for analysis. However, sampling sites are much more limited along the flanks of Mauna Loa. Roadcuts and natural fissures are generally absent, so fully exposed cross sections are unavailable. Nevertheless, we found a site on the SE flank where a roadcut exposed a flow with vesicularity reflecting simple emplacement history.

To avoid potential complexities in size distribution and to obtain maximum pressure resolution, it is best to collect samples from near the top and bottom of the flow to capture the initially erupted modal bubble size before bubble rise and coales- 


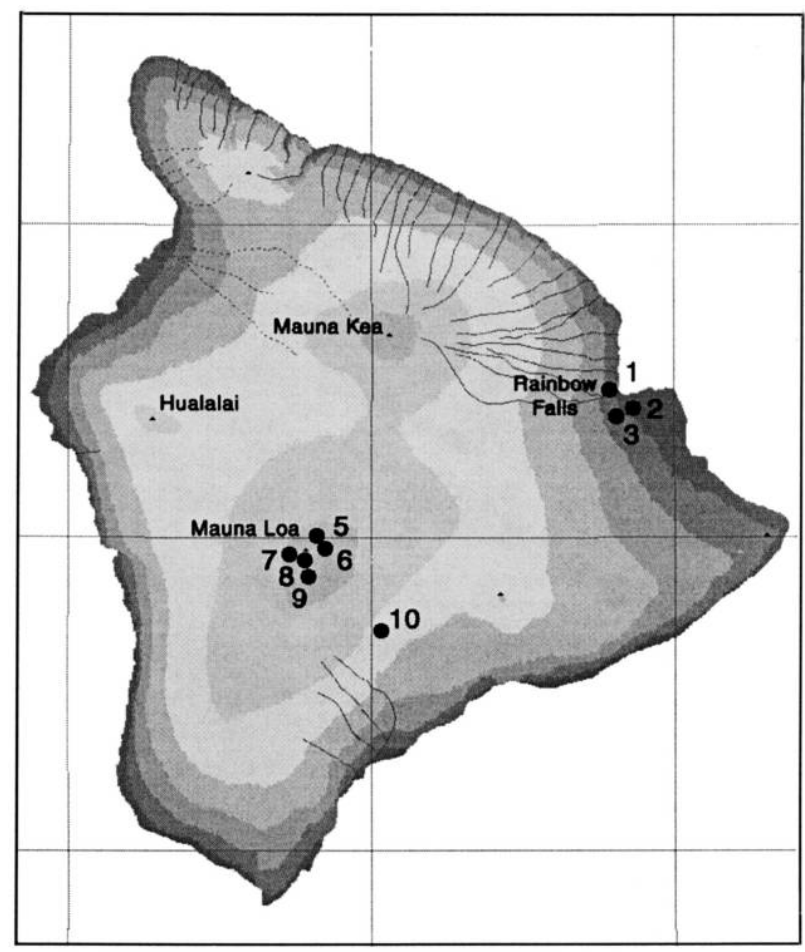

Figure 8. Location map of sampled lava flows on Mauna Loa. Numbers on the map correspond to flow numbers in table 1 .

cence had a chance to alter the size distribution. The theory indicates that samples should be taken from the very top and very base of each flow. However, there is often a glassy rind on the top with evidence of small-scale deformation during pahoehoe emplacement. Likewise, the very base is often emplaced on an underlying pahoehoe surface so that it is deformed. While these small-scale (about a centimeter) deformations do not affect the emplacement history and internal pressure regime, they do introduce unwanted and unnecessary complications at the surface. Consequently, it is more productive to obtain samples from slightly below $(1-3 \mathrm{~cm})$ the top and above the bottom (taking account of this in the $\rho g H$ calculation, of course; figs. $1,2)$. However, in our sampling, we avoided the deep interior of the flow $(30-50 \mathrm{~cm}$ in), where coalescence can alter the bubble size distributions and produce additional modes. Although bubble rise and coalescence can be accounted for (Sahagian 1985; Sahagian et al. 1989), it is better not to introduce an unnecessary potential source of error.

It should be noted that the total gas content (vesicularity) of the flow is irrelevant to the analysis so long as there are enough vesicles to provide a statistically meaningful population because we consider only the ratio between the modal vesicle sizes at top and bottom. (Our samples ranged from $20 \%$ to $40 \%$ bulk vesicularity.) The difference in solubility between top and bottom is small and does not measurably affect bubble size $\mid<1$ vol\% for a 4-m flow; Sahagian and Proussevitch 1992; Proussevitch et al. 1993a, 1993b; Proussevitch and Sahagian 1996). Chemical composition of the lava is irrelevant to the analysis inasmuch as it does not affect lava density. For the Mauna Loa flows, we used a lava density of $2650 \mathrm{~kg} / \mathrm{m}^{3}$.

The Mauna Loa flows we sampled were from twentieth century eruptions (e.g., 1959 flow) and were clean, well preserved, and free of vesicle-filling materials. Flows at the sampling sites were typically 1-2 $\mathrm{m}$ thick to optimize the sensitivity using equation (1) (total $P$ of one bar at top of flow and ideally two bars at base). Photographs of each site were taken before and after sample collection. The elevation of each site was determined from detailed topographic maps and recorded for comparison with elevations derived as a result of our analysis. Samples were collected by breaking pieces off cliff faces or vertical crack surfaces with a chisel and sledgehammer. Collected samples varied in size between about 20 and $30 \mathrm{~cm}$ on a side and were labeled to indicate vertical orientation. In the lab, cylindrical cores (1-inch diameter) were taken from each sample for x-ray scanning.

For each sample in this study, a $2.5-\mathrm{cm}$ cylindrical core was scanned at the HRXCT facility of the University of Texas at Austin. For each core, we obtained 351 contiguous slice images (field of reconstruction $=24 \mathrm{~mm}$; interslice spacing $=47$ $\mu \mathrm{m}$; pixels $=47 \times 47 \mu \mathrm{m}$ ) by using $150-\mathrm{kV}$ radiation at $0.16 \mathrm{~mA}$, a limestone wedge to reduce beamhardening artifacts, 904 views per rotation, and integration times of $132 \mathrm{~ms}$ per view. (Samples 7 and 9 used 1800 views per rotation with integration times of $66 \mathrm{~ms}$ per view.)

\section{Results and Discussion}

This study produced elevations derived from vesicular basalts from Mauna Loa. These elevations were compared to the actual elevations. Table 1 shows the results of our analysis for various lava flows sampled at specific elevations. Each sample analyzed contained from 1500 to 20,000 vesicles, depending on vesicle size, enabling a robust statistical formulation of size distributions. Digital analysis of CT data provided vesicle sizes with an accuracy of $1.6 \%$ with tomographic resolution of 47 $\mu \mathrm{m}$, as described above. The modal size of a dis- 
Table 1. Elevation Calculations for Hawaiian Basalt Flows

\begin{tabular}{|c|c|c|c|c|c|c|}
\hline $\begin{array}{l}\text { Flow number } \\
\text { and sample } \\
\text { location }\end{array}$ & $\begin{array}{l}\text { Flow } \\
\text { thickness } \\
(\mathrm{m})\end{array}$ & $\begin{array}{l}\text { Analyzed } \\
\text { vesicle } \\
\text { population }\end{array}$ & $\begin{array}{c}\text { Modal } \\
\text { size } \\
\left(\mathrm{mm}^{3}\right)\end{array}$ & $\begin{array}{l}\text { Measured } \\
\text { pressure } \\
\text { (atm) }\end{array}$ & $\begin{array}{l}\text { Measured } \\
\text { elevation } \\
(\mathrm{m})\end{array}$ & $\begin{array}{l}\text { Actual } \\
\text { elevation } \\
(\mathrm{m})\end{array}$ \\
\hline $1:$ & & & & & & \\
\hline $\begin{array}{l}\text { Top } \\
\text { Base }\end{array}$ & 1.52 & $\begin{array}{r}4946 \\
13,961\end{array}$ & $\begin{array}{r}1.266 \\
.896\end{array}$ & .972 & 307 & 46 \\
\hline 2: & & & & & & \\
\hline $\begin{array}{l}\text { Top } \\
\text { Base }\end{array}$ & 1.52 & $\begin{array}{r}19,656 \\
9871\end{array}$ & $\begin{array}{r}1.333 \\
.950\end{array}$ & .996 & 45 & 46 \\
\hline 3: & & & & & & \\
\hline $\begin{array}{l}\text { Top } \\
\text { Base }\end{array}$ & 1.78 & $\begin{array}{r}6704 \\
18,946\end{array}$ & $\begin{array}{r}1.118 \\
.742\end{array}$ & .929 & 778 & 335 \\
\hline $\begin{array}{l}\text { 10: } \\
\text { Top } \\
\text { Base }\end{array}$ & 1.24 & $\begin{array}{l}5958 \\
8271\end{array}$ & $\begin{array}{l}.955 \\
.673\end{array}$ & .783 & 1951 & 2388 \\
\hline 5: $\begin{array}{l}\text { Top } \\
\text { Base }\end{array}$ & 1.02 & $\begin{array}{l}6390 \\
5222\end{array}$ & $\begin{array}{l}2.363 \\
1.689\end{array}$ & .676 & 3559 & 3978 \\
\hline 6: & & & & & & \\
\hline $\begin{array}{l}\text { Top } \\
\text { Base }\end{array}$ & 1.22 & $\begin{array}{r}8428 \\
12,653\end{array}$ & $\begin{array}{l}2.362 \\
1.560\end{array}$ & .628 & 4093 & 3978 \\
\hline Top & 1.65 & $\begin{array}{l}6044 \\
9300\end{array}$ & $\begin{array}{l}1.823 \\
1.125\end{array}$ & .704 & 3254 & 3932 \\
\hline $\begin{array}{l}\text { 8: } \\
\text { Top } \\
\text { Base }\end{array}$ & 1.27 & $\begin{array}{l}1974 \\
8096\end{array}$ & $\begin{array}{l}2.488 \\
1.598\end{array}$ & .604 & 4361 & 3932 \\
\hline $\begin{array}{l}\text { 9: } \\
\text { Top } \\
\text { Base }\end{array}$ & 1.68 & $\begin{array}{l}1558 \\
5231\end{array}$ & $\begin{array}{r}1.130 \\
.670\end{array}$ & .648 & 3867 & 3972 \\
\hline
\end{tabular}

tribution is the most useful for pressure sensitivity because it is unaffected by complications resulting from coalescence, external gas input into the flow, loss from the top, and other potentially confounding factors. It can be difficult to precisely determine modal sizes from the size distributions because the peak of the distributions can be flattened or is otherwise ambiguous under some circumstances. Consequently, to increase accuracy, we used a broader part of the distribution curve in our quantitative analysis (dozens of size bins; thousands of vesicles). A regression of the difference in the horizontal position of the right wings (mode and larger) of the distribution curves (in logarithmic scale) between the top and base of the flow provides the most accurate possible modal ratio (better than can be done by eye). This shift then very precisely determines the ratio of modal sizes to be used in equation (1). Some typical size distribution curves are included in figure 6 for illustration and tabulated in table 1.

The accuracy of the technique can be seen in figure 9, a plot of "measured" elevation using our technique versus the actual elevation on Mauna Loa. Perfect results ( 0 error) would lie along the $m=1$ line, and deviation from that line is a measure of error in the analysis.
Sensitivity Analysis and Potential Sources of Error. As in any measurement, there are error sources whose effects must be quantified. There are two ways to assess error in our analysis. The first, a simple comparison of analytical results with actual elevations (fig. 9), results in a standard deviation (between measured and actual) of $\sigma=372 \mathrm{~m}$, which is small relative to the elevation changes we consider in major tectonic events. This simple "empirical" approach to the error depends on the number of samples analyzed and is thus not intrinsic to the technique. The error can be reduced simply by taking more samples (to within budgetary constraints). These results suggest that even with a small number of measurements, the accuracy of the technique is sufficient to resolve paleoelevations for application to various geologic problems.

The second approach to error assessment is a factor analysis of the various error sources within the procedure. These sources can be ascribed to the three major parameters in equation (1) above: vesicle size, hydrostatic pressure, and sea level atmospheric pressure.

Measurement of Vesicle Sizes. The discretization of vesicles into voxelized representations using $\mathrm{x}$-ray tomography introduces a source of error in the 


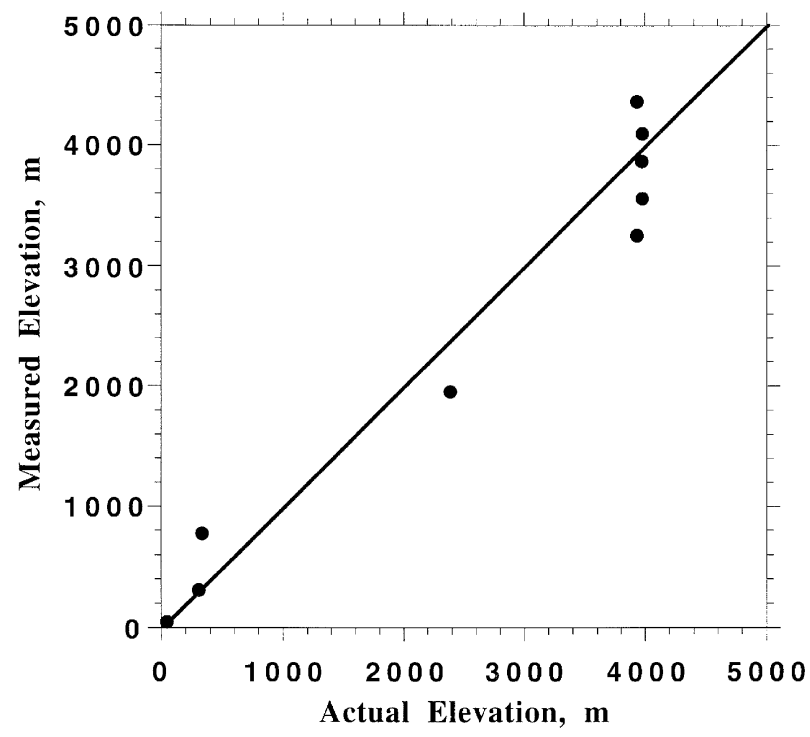

Figure 9. Results of analysis of using vesicular basalt as a measure of paleoelevation. Perfect results would lie along the diagonal line.

vesicle volume. This error can be calculated on the basis of the relative size of vesicles and the voxels with which they are constructed. Based on a vesicle diameter of $1 \mathrm{~mm}$ with a linear measurement resolution of $47 \mu \mathrm{m}$, error arises from the uncertainty of including or not including voxels from the surface of a vesicle, where the boundary between rock and air cuts through a voxel. This uncertainty regarding the nature of the boundary voxel makes a maximum measurement deviation of one complete voxel length, or $\sigma=47 \mu \mathrm{m}$. If we were to make only a single measurement and on that basis leave the entire exterior shell of voxels either in or out of the vesicle, the volumetric error, $\sigma_{\mathrm{v}}$, would be $(R+$ $2 \sigma)^{3} / R^{3}=(500+94)^{3} / 500^{3}=1.67$ or $\sigma_{\mathrm{v}}=67 \%$. However, we make this measurement for every voxel in the exterior shell. The number of voxels included in that exterior shell is theoretically $4 \pi(\text { radius in voxels })^{2}=4 \pi(1000 / 47 / 2)^{2}=1422$ voxels. This leads to a total measurement error of the volume of the vesicle as $\sigma_{\mathrm{v}} /\left(N_{\text {population }}\right)^{1 / 2}=67 \% /$ $(1422)^{1 / 2}=1.77 \%$. This analytical formulation for the surface area of the vesicle does not account for the lattice orientation of cubic voxels but gives an approximate analytical treatment of the problem. The actual number of voxels is easily counted and for one specific example is 1480, leading to a slightly smaller error of $1.74 \%$. This leads to an error in paleopressure of $\pm 17 \mathrm{mb}$ or $\pm 190 \mathrm{~m}$.

Hydrostatic Pressure at the Base of Lava Flow.
Densities of lavas are known to within about $\pm 1 \%$. For basaltic flows, the density of the fluid lava is used because, at the time the top and bottom solidify, the flows do not include any highly vesicular zones of foams in which interaction between bubbles is strong enough to support the overlying fluid and thus reduce the pressure at the base of the flow to below hydrostatic. Gravity is known "perfectly." The thickness of a flow can be measured in the field, but we will account for potential error resulting from unrecognized minor inflation or deflation after solidification of upper and lower parts of the flow. Each centimeter of measurement error or inflation/deflation would lead to an error of $\pm 33 \mathrm{~m}$ in elevation. Although inflation/deflation is readily identified in the field, we include an error term to account for 10 $\mathrm{cm}$ of inflation/deflation, providing an elevation uncertainty of $\pm 330 \mathrm{~m}$ for a typical 3-m flow. However, with judicious choice of sampling sites, this source of error should be reduced.

Sea Level Pressure at the Time of Eruption. There are normal variations in barometric pressure due to changing weather conditions. Typically, the time scale of these variations is no longer than several days for synoptic systems. (Seasonal averaged variations are smaller.) Taking a conservative approach, however, variations in barometric pressure (due to weather) at the time of eruption of up to 30 $\mathrm{mb}$ lead to an uncertainty of about $\pm 150 \mathrm{~m}$ for a given flow. It is unlikely that a hurricane or other very low pressure system will have been present throughout the cooling of a lava flow and very likely that barometric variations over several days will have averaged out in the slowly cooling lava, but a conservative estimate is $\pm 150 \mathrm{~m}$.

The total error from the various contributions is thus estimated conservatively as $\left[(190)^{2}+\right.$ $\left.(330)^{2}+(150)^{2}\right]^{1 / 2}$ or about $\pm 410 \mathrm{~m}$ (using the larger errors above). The different approaches to error assessment agree (372 vs. $410 \mathrm{~m}$ ), indicating that in cases when the actual elevations of samples are not known a priori, the proposed analysis can be used to reliably determine paleoelevations to within $400 \mathrm{~m}$ of uncertainty (or better with multiple sampling).

\section{Conclusions}

Vesicle size distributions as a function of stratigraphic position in lava flows depend on atmospheric pressure, so it is possible to determine paleopressure and thus paleoelevation of emplacement from analysis of vesicular basalts. A generalized diagrammatic flow chart for determining paleoelevation from vesicular lavas is indicated in figure 7 . 
Vesicle Size Distribution Measurement. Size distributions can be accurately determined with various techniques. The 2-D techniques are limited in applicability to "ideal" cases of spherical, convex, and/or noninterconnected vesicles. The most generally useful technique is HRXCT because it not only can be used as a measure of vesicularity and size distributions but can also be used for interconnectivity and permeability studies. The accuracy of HRXCT for measuring size distributions is limited by its resolution, which, for a scan resolution of $47 \mu \mathrm{m}$, corresponds to an elevation resolution of $\pm 190 \mathrm{~m}$.

Identifying Individual Vesicles. Many vesicles are partially coalesced or separated by films thinner than observational resolution. It is possible (and necessary) to separate these vesicles and assign them individual identities for valid size distribution analysis. This can be done numerically by "peeling" layers of voxels until all vesicles have disappeared and subsequently reconstructing the vesicles one voxel layer at a time.

Lava Emplacement History. The vesicularity profiles observed in the field can be used to gain insights regarding a flow's emplacement history. Flow inflation can be identified by multiple vesicle zones in the flow interior that are caused by new parcels of magma introducing new bubbles during flow solidification. Flow deflation can be identified by "missing" massive zones in flows with welldeveloped upper vesicular zones, indicating that the volume of lava from which bubbles rose and coalesced has been removed. Only flows with simple emplacement history should be used in paleoelevation studies.

Validation of Vesicular Basalts as an Elevation Measure. Our analysis of Hawaiian basalts from low, intermediate, and high elevations demonstrates that elevations can be determined from vesicular basalts with a resolution of $\pm 400 \mathrm{~m}$, including the \pm 190 m uncertainty from HRXCT size distribution analysis.

Application to Paleoelevation and Epeirogeny. As is indicated by the test of the method based on known Mauna Loan elevations, our technique can subsequently be applied to paleoelevations for the purpose of documenting the timing and magnitude of epeirogenic events in highland areas. This could be a useful new tool to be added to the existing arsenal of proxies for determining paleoelevations. There are several key tectonic and epeirogenic events in Cenozoic time that have been the subject of some controversy regarding timing and history. The problem of epeirogenic plateau uplift of the Colorado Plateau and adjacent Rocky Mountains, for example, has been an issue of concern for many decades (Dutton 1880; McGetchin et al. 1980; Morgan and Swanberg 1985; Burchfiel et al. 1992; Heller et al. 1993; Spencer 1996). Other problematic areas include Tibet (Derbyshire 1996; Fielding 1996), Africa (Summerfield 1985; Sahagian 1988; Brown et al. 1990), and the Andes (Kroonenberg 1990), where questions remain regarding uplift history. It is our hope that our newly developed technique for determining paleoelevations on the basis of vesicular basalts will be a useful addition to the arsenal of tools being employed by the geologic community for reconstructing paleogeography and epeirogeny.

Other Applications. While we chose to first apply our new vesicle measurement techniques to volcanological problems (vesicular basalt), there are many other applications as well. These include but are not limited to crystal size distributions and orientations, crystal clustering, sedimentary grain and pore sizes, ceramic foams, industrial quality control, and virtually any other application that involves the "raisin bread problem" of a distribution of particles embedded in a medium.

\section{A C K N O W L E D G M E N T S}

We are grateful to Dave Meeker for help with the statistical treatment of our error analysis, to Richard Ketcham and Matthew Colbert for technical assistance with x-ray tomography, and to three anonymous reviewers for insightful reviews. This work was supported by a grant from the National Science Foundation (NSF; EAR-9614747). The HRXCT facility at the University of Texas at Austin is an NSF shared multiuser facility supported in part by grant EAR-0004082.

\section{R E F E R E N C E S C I T E D}

Abe, Y., and Matsui, T. 1986. Early evolution of the earth: accretion, atmosphere formation, and thermal history. I. Geophys. Res. 91:E291-E302.

Azbel, I. Y., and Tolstikhin, I. N. 1990. Geodynamics, magmatism, and degassing of the earth. Geochim. Cosmochim. Acta 54:139-154.
1993. Accretion and early degassing of the earth: constraints from PU-U-I-XE isotopic systematics. $\underline{\text { Me- }}$ teoritics 28:609-621.

Barron, E. J. 1985. Explanations of the Tertiary global cooling trend. Palaeogeogr. Palaeoclimatol. Palaeoecol. 50:45-61. 
Beghoul, N., and Barazangi, M. 1989. Mapping high Pn velocity beneath the Colorado Plateau constrains uplift models. I. Geophys. Res. 94:7083-7104.

Beghoul, N.; Barazangi, M.; and Isacks, B. 1993. Lithospheric structure of Tibet and western North America: mechanisms of uplift and a comparative study. I. Geophys. Res. 98:1997-2016.

Bird, P. 1979. Continental delamination and the Colorado Plateau. I. Geophys. Res. 84:7561-7573.

Brown, R. W.; Rust, D. J.; Summerfield, M. A.; Gleadow, A. J. W.; and Wit, M. C. J. D. 1990. An early Cretaceous phase of accelerated erosion on the south-western margin of Africa: evidence from apatite fission track analysis and the offshore sedimentary record. Nucl. Tracks Radiat. Meas. 17:339-350.

Burchfiel, B. C.; Cowen, D. S.; and Davis, G. A. 1992. Tectonic overview of the Cordillera orogen in the western United States. In Burchfiel, B. C.; Lipman, P. W.; and Zoback, M. I., eds. The Cordillera orogen, conterminous U.S. Boulder, Colo., Geol. Soc. Am., p. 407-479.

Derbyshire, E. 1996. Quaternary glacial sediments, glaciation style, climate and uplift in the Karakoram and northwest Himalaya-review and speculations. Palaeogeogr. Palaeoclimat. Palaeoecol. 120:147-157.

Dickinson, W. R., and Snyder, W. S. 1979. Geometry of subducted slabs related to San Andreas transform. I. Geol. 87:609-627.

Dullien, F. 1973. Photomicrographic pore size distributions using quantitative stereology and application of results in tertiary petroleum recovery, pore structure and properties of materials. 1. Methods of determination of pore structure. Prague, Academia, p. C173-C186.

Dutton, C. E. 1880. Report on the geology of the high plateaus of Utah. Washington, D.C., Government Printing Office.

Fielding, J. 1996. Tibet uplift and erosion. Tectonophysics 260:55-84.

Forest, C. E.; Molnar, P.; and Emanuel, K. A. 1995. Palaeoaltimetry from energy conservation principles. Nature 374:347-350.

Gregory, K., and Chase, C. 1992. Tectonic significance of paleobotanically estimated climate and altitude of the late Eocene erosion surface, Colorado. Geology 20: 581-585.

- 1994. Tectonic and climatic significance of a late Eocene low-relief high-level geomorphic surface, Colorado. I. Geophys. Res. 99:20,141-20,160.

Gregory, K. M. 1994. New prospects in old bubbles. Nature 372:407-408.

Gregory, K. M., and McIntosh, W. C. 1996. Paleoclimate and paleoelevation of the Oligocene Pitch-Pinnacle flora, Sawatch Range, Colorado. Geol. Soc. Am. Bull. 108:545-561.

Heller, P.; Beekman, F.; Angevine, C.; and Cloetingh, S. A. 1993. Cause of tectonic reactivation and subtle uplifts in the Rocky Mountain region and its effect on the stratigraphic record. Geology 21:1003-1006.

Higgins, M. D. 1994. Numerical modeling of crystal shapes in thin sections: estimation of crystal habit and true size. Am. Mineral. 79:113-119.

Ketcham, R., and Carlson, W. 2001. Acquisition, optimization and interpretation of x-ray computed tomographic imagery: applications to the geosciences. Comput. Geosci. 27:381-400.

Kroonenberg, S. B. 1990. Late Cenozoic uplift and paleogeography of the Colombian Andes-constraints on the development of high-Andean biota. Geol. Mijnbouw 69:279.

Kutzbach, J.; Prell, W.; and Ruddiman, W. 1993. Sensitivity of Eurasian climate to surface uplift of the Tibetan Plateau. I. Geol. 101:177-190.

Kutzbach, J. E.; Guetter, J.; Ruddiman, W. F.; and Prell, W. L. 1989. The sensitivity of climate of Late Cenozoic uplift in southeast Asia and the American southwest: numerical experiments. I. Geophys. Res. 94:18,393-18,407.

Loomis, K., and Ingle, N. 1994. Subsidence and uplift of the Late Cretaceous Cenozoic margin of California: new evidence from the Gualala and Point Arena basins. Geol. Soc. Am. Bull. 106:915-931.

Lucchitta, I. 1990. Role of heat and detachment in continental extension as viewed from the eastern Basin and Range Province in Arizona. Tectonophysics 174:77-114.

Lucchitta, I., and Morgan, M. 1998. The Upper Miocene Bouse formation as an indicator for Late Cenozoic uplift of the Colorado Plateau. Geol. Soc. Am. Abstr. Program, 1998 Rocky Mountain Section Meeting.

Luo, X., and Vasseur, G. 1995. Modelling of pore pressure evolution associated with sedimentation and uplift in sedimentary basins. Basin Res. 7:35-52.

Mangan, M. 1990. Crystal size distribution systematics and the determination of magma storage times: the 1959 eruption of Kilauea volcano, Hawaii. J. Volcanol. Geotherm. Res. 44:295-302.

Marsh, B. D. 1988. Crystal size distributions (CSD) in rocks and the kinetics and dynamics of crystallization. 1. Theory. Contrib. Mineral. Petrol. 99:277-291.

McDonough, K. J., and Cross, T. A. 1991. Late Cretaceous sea level from a paleoshoreline. I. Geophys. Res. 96: 6591-6608.

McGetchin, T. R.; Burke, K. C.; Thompson, G. A.; and Young, R. A. 1980. Mode and mechanisms of plateau uplifts. In Bally, A. W.; Bender, L.; McGetchin, T. R.; and Walcott, R. I., eds. Dynamics of plate interiors (Geodynamics Series Vol. 1). Washington, D.C., Am. Geophys. Union; Boulder, Colo., Geol. Soc. Am., p. 99-110.

Meyer, H. 1992. Lapse rates and other variables applied to estimating paleoaltitudes from fossil floras. Palaeogeogr. Palaeoclim. Palaeoecol. 99:71-99

Molnar, P., and England, P. 1990. Late Cenozoic uplift of mountain ranges and global climate change: chicken or egg? Nature 346:29-34.

Morgan, P., and Swanberg, C. A. 1985. On the Cenozoic uplift and tectonic stability of the Colorado Plateau. I. Geodynamics 3:39-63.

Nadin, P., and Kusznir, N. 1995. Paleocene uplift and Eocene subsidence in the northern North Sea basin 
from 2D forward and reverse stratigraphic modelling. I. Geol. Soc. Lond. 152:833-848.

Parsons, T., and McCarthy, J. 1995. The active southwest margin of the Colorado Plateau: uplift of mantle origin. Bull. Geol. Soc. Am. 107:139-147.

Parsons, T.; Thompson, G.; and Sleep, N. 1994. Mantle plume influence on the Neogene uplift and extension of the United States Western Cordillera. Geology 22:83-86.

Peterson, T. 1996. A refined technique for measuring crystal size distributions in thin section. Contrib. Mineral. Petrol. 124:395-405.

Proussevitch, A. A., and Sahagian, D. L. 1996. Dynamics of coupled diffusive and decompressive bubble growth in magmatic systems. I. Geophys. Res. 101: $17,447-17,156$.

- 1998. Dynamics and energetics of bubble growth in magmas: analytical formulation and numerical modeling. I. Geophys. Res. 103:18,223-18,251.

- 2001. Recognition and separation of discrete objects within complex 3D voxelized structures. Comp. Geosci. 27:441-454.

Proussevitch, A. A.; Sahagian, D. L.; and Kutolin, V. 1993a. Stability of foams in silicate melts. J. Volcanol. Geotherm. Res. 59:161-178.

Proussevitch, A. A.; Sahagian, D. L.; and Anderson, A. T. 1993b. Dynamics of diffusive bubble growth in magmas: isothermal case. L. Geophys. Res. 98: 22,283-22,308.

Rowe, T.; Kappelman, J.; Carlson, W.; Ketham, R.; and Denison, C. 1997. High-resolution computed tomography: a breakthrough technology for earth scientists. Geotimes 42:23-27.

Ruddiman, W. F., and Kutzbach, J. E. 1989. Forcing of late Cenozoic Northern Hemisphere climate by plateau uplift in southern Asia and the American West. J. Geophys. Res. 94:18,409-18,427.

Russ, J. C. 1986. Practical stereology. New York, Plenum, $185 \mathrm{p}$.

Sahagian, D. L. 1985. Bubble migration and coalescence during the solidification of basaltic lava flows. I. Geol. 93:205-211.

- 1987. Epeirogeny and eustatic sea level changes as inferred from Cretaceous shoreline deposits: application to central and western United States. $\underline{\text { L. Geo- }}$ phys. Res. 92:4895-4904.

- 1988. Epeirogenic motions of Africa as inferred from Cretaceous shoreline deposits. Tectonics 7: 125-138.

- 1989. Epeirogeny of Europe and western Asia. Cretaceous Res. 10:33-48.

Sahagian, D. L.; Anderson, A. T.; and Ward, B. 1989. Bubble coalescence in basalt flows: comparison of a numerical model with natural examples. Bull. Volcanol. 52:49-56.

Sahagian, D. L., and Maus, J. E. 1994. Basalt vesicularity as a measure of atmospheric pressure and paleoelevation. Nature 372:449-451.
Sahagian, D. L., and Proussevitch, A. A. 1992. Bubbles in volcanic systems. Nature 359:485.

- 1998. 3D particle size distributions from 2D observations: stereology for natural applications. J. Volcanol. Geotherm. Res. 84:173-196.

Song, S.; Jones, K.; Lindquist, W.; Dowd, B.; and Sahagian, S. 2001. Synchrotron $x$ ray computed microtomography (CMT) studies of vesiculated basaltic rocks. Bull. Volcanol. 63:252-263.

Spencer, J. E. 1996. Uplift of the Colorado Plateau due to Lithosphere attenuation during Laramide low-angle subduction. L. Geophys. Res. 101:13,595-13,609.

Spencer, J. E., and Patchett, J. 1997. Sr isotope evidence for a lacustrine origin for the upper Miocene to Pliocene Bouse Formation, lower Colorado River trough, and implications for timing of Colorado Plateau uplift. Geol. Soc. Am. Bull. 109:767-778.

Summerfield, M. A. 1985. Plate tectonics and landscape development on the African continent. In Morisawa, M., and Hack, J. T., eds. Tectonic geomorphology. London, Allen Unwin, p. 27-51.

Tajika, E., and Matsui, T. 1993. Degassing history and carbon cycle of the earth-from an impact-induced steam atmosphere to the present atmosphere. Lithos 30:267-280.

Toramaru, A. 1990. Measurement of bubble size distributions in vesiculated rocks with implications for quantitative estimation of eruption processes. J. Volcanol. Geotherm. Res. 43:71-90.

Tudhope, A.; Buddemeier, R.; Chilcott, C.; and Berryman, K. 2000. Alternating seismic uplift and subsidence in the late Holocene at Madanq, Papua New Guinea: evidence from raised reefs. I. Geophys. Res. 105:13,797-13,807.

Underwood, E. E. 1970. Quantitative stereology. Reading, Mass., Addison-Wesley, $274 \mathrm{p}$.

Williams, D. R., and Pan, V. 1992. Internally heated mantle convection and the thermal and degassing history of the earth. I. Geophys. Res. 97:8937-8950.

Wolfe, J. 1995. Paleoclimatic estimates from Tertiary leaf assemblages. Annu. Rev. Earth Planet. Sci. 23:119-142.

Wolfe, J.; Forest, C.; and Molnar, P. 1998. Paleobotanical evidence of Eocene and Oligocene paleoaltitudes in midlatitude western North America. Geol. Soc. Am. Bull. 110:664-678.

Wolfe, J.; Gregory-Wodzicki, K.; Molnar, P.; and Mustoe, G. 2000. Paleobotanical evidence for the development of high altitudes during the early Eocene in northwestern North America. Swed. Geol. Soc. Bull. 122:186-187.

Wolfe, J., and Shorn, H. 1989. Paleoecologic, paleoclimatic, and evolutionary significance of the Oligocene Creede flora, Colorado. Paleobiology 15:180-198.

Ziegler, A. M.; Rowley, D. B.; Lottes, A. L.; Sahagian, D. L.; Hulver, M. L.; and Gierlowski, T. C. 1985. Paleogeographic interpretation: with an example from the Mid-Cretaceous. Annu. Rev. Earth Planet. Sci. 13:385-425.

Ziegler, A. M.; Scotese, C. R.; McKerrow, W. S.; Johnson, M. E.; and Bambach, R. K. 1979. Paleozoic paleogeography. Annu. Rev. Earth Planet. Sci. 7:473-502. 